\title{
Analysis of the Thrips Fauna (Insecta: Thysanoptera) on Flowers of Roses in Western Part of Romania
}

\author{
Ana - Maria VIRTEIU ${ }^{1 *}$, Ioana GROZEA ${ }^{1}$, Ramona STEF ${ }^{1}$, Alin CARABET ${ }^{1}$, Levente MOLNAR ${ }^{1}$, Teodora \\ FLORIAN $^{2}$ and Veaceslav MAZARE ${ }^{1}$ \\ ${ }^{1}$ Department of Biology and Plant Protection, Banat's University of Agricultural Sciences and \\ Veterinary Medicine "King Michael I of Romania" from Timisoara \\ 119 Calea Aradului, Timisoara, Romania \\ ${ }^{2}$ Department of Environmental and Plant Protection, University of Agricultural Science and Veterinary \\ Medicine Cluj - Napoca \\ 3 - 5 Calea Manastur, Cluj - Napoca, Romania \\ *Corresponding author: anamaria.badea@gmail.com \\ Bulletin USAMV series Agriculture 72(2)/2015 \\ Print ISSN 1843-5246; Electronic ISSN 1843-5386 \\ DOI 10.15835/buasvmcn-agr: 11487
}

\begin{abstract}
Thrips fed especially on flowers petals after bud break, causing losses in blossom quality. This research work covers the observations of the species composition of thrips and the periods of the occurrence of the particulars species of thrips and their numerousness. The analysis of the thrips specific diversity pointed out a taxonomic spectrum of 12 species, four of those species of thrips, Frankliniella intonsa, Taeniothrips inconsequens, Thrips fuscipennis and Thrips major var. banatica, were recorded as the most important insect pest on rose in western part of Romania. Regarding to the geographical distribution, our studies highlights the dominance of the WestPalaeartic elements.
\end{abstract}

Key words: geographical distribution, rose flowers, species diversity,

\section{INTRODUCTION}

Thrips are found in all kinds of vegetation: flowers, foliage, under bark of live or dead trees, litter, in stored bulbs and a few from galls or distort leaves. Almost all of them are phytophagous, only a few being predatory. Some species constitute serious agriculture pests. However, others species are considerate beneficial, since they may facilitate pollination or decomposition (Palmer et al., 1989). Thrips are cosmopolitan, with most species found in tropical regions, many in the temperate zone, but only few in the artic regions (Lewis, 1973).

\section{MATERIALS AND METHODS}

Studies of Thysanoptera were realized at the Young Naturalists Station in Timisoara, on five rose varieties (Virgo, Pascaly, Golden Shower, Gloria Day and Flamingo), over the years 2012 2014. The present studies have taken into account the identification of thrips fauna damaging roses.

Thrips are more active inside of the flowers, so counting of thrips is very difficult in the fields. Therefore, in order to achieve the objectives set were used the flowers and flowers buds collecting method - thus, for each variety were harvested by 5 blossoming rose. Every 5 inflorescences collected were introduced separately, in glass containers with airtight lid and being transported in Entomology Laboratory. Harvests were performed at 15-day intervals. To accurately estimate the population densities of thrips, flowers were tagged 
at the time which mass flights of thrips occurred from red flowers to white flowers.

\section{RESULTS AND DISCUSSION}

The results obtained after collection made during June - September 2012 - 2014 from rose culture have highlighted the following:

- It was found that in STN Timisoara experimental field, in a warming climate and aridity of current period, thrips populations have grown excessively.

- The numerical abundence reveals a total of 5028 adults of the five rose varieties which belong only to 12 species.

- 7 species of thrips were identified as damaging crops rose in all five varieties studied. Three of the species known as harmful the rose culture, Frankliniella intonsa, Thrips fuscipennis and Thrips major var. banatica were present in high percentages. Among the other species collected: Frankliniella occidentalis and Thrips tabaci are considered polyphagous pests; Frankliniella tritici and Thrips fulvipes are common species both herbaceous plants, but also on woody essences.

- Four of the five varieties studied, namely: Pascaly, Flamingo, Gloria Day și Virgo - the dominant species was Frankliniella intonsa, and to the Golden Shower variety - the dominant species was Frankliniella occidentalis (table 1). Highest population density of these thrips occurred during the blooming stage.

- Also, the least represented species in samples taken from all varieties was Thrips fulvipes

- The varieties least attacked by thrips proved to be Virgo and Pascaly, tolerant varieties were Golden Shower and Gloria Day and the most susceptible to thrips attack proved Flamingo variety.

- As a conclusion, we point out that the varieties least attacked were those who had white and white - cream flowers, tolerant varieties were those with yellow and yellow - reddish flowers, and the most attacked were those with red flowers. We emphasize that the varieties with white flower had the most visible attack; qualitative impairment is most obvious compared to varieties with red flowers.

Trophic levels. According to our study, all the thrips species are polyphagous: 8 species are flower and flower buds feeder (rarely leaves and fruits feeders) and 4 species are leaves feeders.

Trophic relation. The results of our qualitative dietary analysis provide data about the kinds of foods consumed by the thrips species, but does not provide data on the quantity or quality of the foods. Our data represent a three year span of time, and we made no attempt at determining monthly or seasonal variations because sample sizes were often too small. We did not observe any changes in the seasonal diets of these thrips. Forty six, 66 percent of the 12 thrips species in STN Timisoara were herbaceous, $25 \%$ woody, $16.67 \%$ herbaceous, rarly woody and $16.67 \%$ are both herbaceous and woody.

Geographical distribution. The geographical distribution of thrips species on roses presents 4 W-Palearctic, 3 cosmopolite, 2 Palearctic, 1 EuroSiberian, 1 European and 1 Holartic species.

\section{CONCLUSION}

The component populations of the Thysanoptera association on rose culture belong to 12 species, which denotes a rich diversity of the coenosis inhabiting a single host plant. Structural indicators values indicate species Frankliniella intonsa as characteristic species on rose, with the highest values of relative abundance and frequency in four of the five varieties studied, as followed: Pascaly, Flamingo, Gloria Day și Virgo.

\section{REFERENCES}

1. Lewis $\mathrm{T}$ (1973). Thrips. Their biology, ecology and economic importance. Academic Press, London.

2. Palmer JM, Mound LA, DuHeaume GJ(1989). Thysanoptera. Wallingford:CAB, (CIE Guides to Insects of Importance to Man, 2): 74. 